University of Nebraska - Lincoln

DigitalCommons@University of Nebraska - Lincoln

USGS Staff -- Published Research

US Geological Survey

1994

\title{
Stable isotopes of oxygen and hydrogen in the Truckee River-Pyramid Lake surface-water system. 3. Source of water vapor overlying Pyramid Lake
}

Larry Benson

U.S. Geological Survey, great.basin666@gmail.com

J.W. C. White

University of Colorado, Boulder

Follow this and additional works at: https:// digitalcommons.unl.edu/usgsstaffpub

Part of the Geology Commons, Oceanography and Atmospheric Sciences and Meteorology Commons, Other Earth Sciences Commons, and the Other Environmental Sciences Commons

Benson, Larry and White, J. W. C., "Stable isotopes of oxygen and hydrogen in the Truckee River-Pyramid Lake surface-water system. 3. Source of water vapor overlying Pyramid Lake" (1994). USGS Staff-- Published Research. 1016.

https://digitalcommons.unl.edu/usgsstaffpub/1016

This Article is brought to you for free and open access by the US Geological Survey at DigitalCommons@University of Nebraska - Lincoln. It has been accepted for inclusion in USGS Staff -- Published Research by an authorized administrator of DigitalCommons@University of Nebraska - Lincoln. 
Stable isotopes of oxygen and hydrogen in the Truckee River-Pyramid Lake surface-water system. 3. Source of water vapor overlying Pyramid Lake

L. V. Benson

U.S. Geological Survey, Boulder Laboratory, 3215 Marine Street, Boulder, Colorado 80303

J. W. C. White

Department of Geological Sciences, Campus Box 250, University of Colorado, Boulder 80309

\begin{abstract}
During 1988 and 1989 , a series of water-vapor extractions were conducted in the Pyramid Lake basin to determine the source of moisture that overlies the lake. Calculations of the isotopic and water-vapor balances were made from isotopic and meteorological data from the Pyramid Lake and Reno, Nevada, areas. The results indicate that in the warm season, most of the moisture that overlies the lake is derived from evaporation as opposed to advected moisture. Isotopic fluxes at the lake surface can be approximated by climatic data from the lake site, which simplifies the calculation of this input in numerical simulations of the isotopic evolution of the lake.
\end{abstract}

The stable-isotopic composition of a lake is a function of the volume-weighted isotopic values of each component of the lake's hydrologic balance. Researchers have used the stable-isotope history of a lake together with the volume-weighted isotopic composition of easily measured components of the hydrologic balance to estimate the stable-isotope values or amounts of less easily measured components of the hydrologic balance (see IAEA 1970, 1979). It is usually relatively simple to quantify the amounts and isotopic compositions of components of the surface-water system and the isotopic composition of groundwater. It is often more difficult to quantify the amount and direction of groundwater transport across the sediment-water interface and the amount and isotopic composition of lake surface evaporation.

The isotopic value of water evaporated from a lake is highly dependent on the isotopic value

\footnotetext{
Acknowledgments

We express our appreciation to those who assisted in sampling, including Jim Davis, Dan Mosley, and Nancy Vucinich. Special thanks to Irving Friedman, who loaned us the copper traps used for water-vapor extraction; to Carol Kendall and Tyler Coplen, who oversaw the isotopic analyses; to James Ashby, who maintained the weather stations; and to Steve Hostetler, who extracted the meteorological data from the weather-station database and stratified the wind data for the Sutcliffe and Northshore sites. We also thank Zell Peterman, Steve Hostetler, and Pieter Tans for reviews of earlier versions of this manuscript.
}

of water vapor that overlies the lake (Craig and Gordon 1965); however, only a few studies (Fontes and Gonfiantini 1970; Fontes et al. 1970; Zimmermann and Ehhalt 1970) have attempted measurement of the isotopic content of water vapor found within a lake basin. The isotopic value of moisture evaporated from the surface of a lake is a necessary input to simulations of the isotopic evolution of the lake. If this value is not measured, the default option has usually been to assume that the isotopic composition of the turbulent mixed layer (hereafter termed the mixed layer) that overlies the lake is in equilibrium with precipitation (or runoff) that falls in the catchment area of the lake basin. This option may be a reasonable approximation for humid regions, such as the northeastern United States, where free-surface evaporation is relatively small (0.6-0.8 $\mathrm{m} \mathrm{yr}^{-1}$, Farnsworth et al. 1982) and where relatively moist air masses often occupy the lake basin. In arid regions such as the Great Basin of the western United States, this may be a poor approximation, because warm-season lake evaporation is relatively large (1.2$2.0 \mathrm{~m} \mathrm{yr}^{-1}$ ) and air masses that occupy or cross the Great Basin are relatively dry.

The purpose of this study is to determine the source of moisture in the mixed layer that overlies Pyramid Lake, Nevada. In particular, we wish to assess the influence of evaporation on the stable-isotope composition of the mixed layer. 


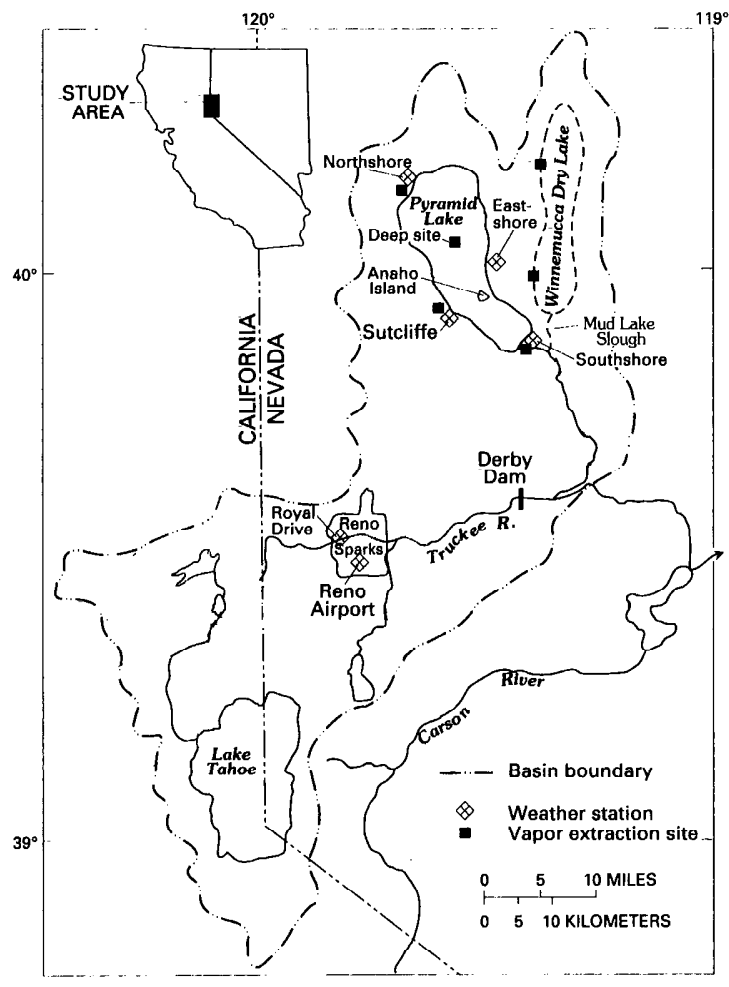

Fig. 1. Map of the Truckee River system, Pyramid Lake, and Winnemucca (Dry) Lake subbasins.

Pyramid Lake, the terminus of the Truckee River surface-water system, is locatcd $\sim 50 \mathrm{~km}$ northeast of Reno within a hydrologically closed basin (Fig. 1). Ongoing studies of the isotopic evolution of Pyramid Lake (Benson 1994; Hostetler and Benson 1994) require determination of the manner in which lake evaporation and interbasin advected moisture combine to form the mixed layer that overlies the lake. To make this determination, we conducted a series of water-vapor extraction experiments in 1988 and 1989. Water vapor was extracted at three land sites located near weather stations and at a raft site located near the center of Pyramid Lake (Fig. 1). Two extractions were also conducted in the adjacent Winnemucca (Dry) Lake subbasin in order to characterize the isotopic composition of water vapor contained in relatively dry air found east of Pyramid Lake. In addition, precipitation samples were collected from the western shore of the lake at the Sutcliffe site (Fig. 1) in order to estimate, via the equilibrium assumption,

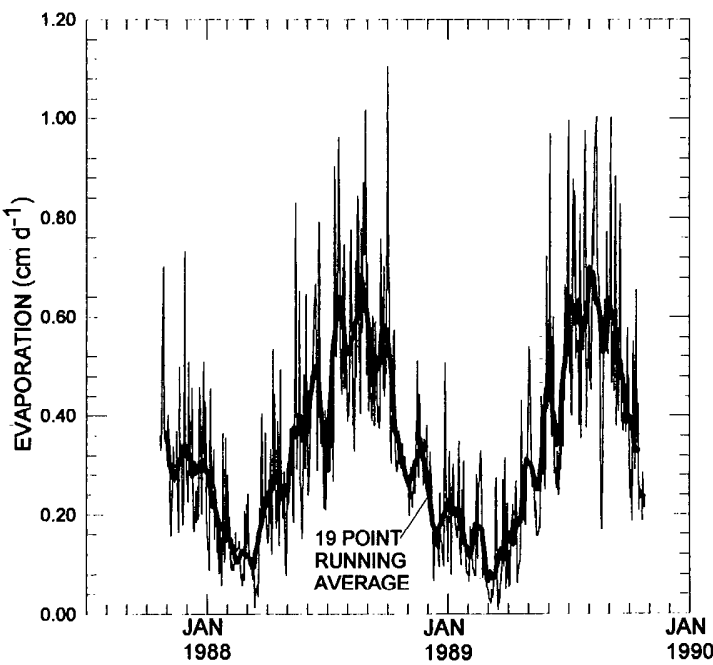

Fig. 2. Evaporation from Pyramid Lake, 12 October 1987-12 October 1989 (S. Hostetler unpubl. modeling results).

the isotopic composition of water vapor derived from westerly storm systems.

Vapor-phase extractions were conducted during the season of highest evaporation (June through November, Fig. 2). During this season, the wind regime in the Pyramid Lake basin is strongly influenced by basin-scale convective processes. During daylight hours, radiative heating of the land surface around the lake induces a lake breeze. A weak land breeze is initiated during the evening when the surrounding land surface cools. Diurnal values of wind direction at the Sutcliffe and Northshore sites (Hostetler and Benson 1993) indicate that in summer, there is a land breeze between 1900 and 0700 hours at Sutcliffe. Between 0700 and 1900 hours, there is a lake breeze with the wind shifting from northeast to north at $\sim 1500$ hours. At the Northshore site, there is a summertime land breeze between 1800 and 0800 hours and usually there is a lake breeze between 0800 and 1900 hours.

\section{Methods}

Water-vapor extractions ranging in duration from 30 to $190 \mathrm{~min}$ were accomplished by pumping through two doubly coiled copper traps joined in series and immersed in an insulated cylinder containing a mixture of dry ice and butylcellulose. Both traps contained copper mesh to increase the surface area avail- 
Table 1. Stable isotopes in precipitation at the Sutcliffe site: \%o relative to VSMOW; subscript $p$-precipitation; $\delta_{v}-$ del value of vapor phase calculated to be in equilibrium with precipitation.

\begin{tabular}{|c|c|c|c|c|c|c|}
\hline & $\delta^{18} \mathrm{O}_{r}$ & $\delta^{2} \mathrm{H}_{p}$ & \multirow{2}{*}{$\begin{array}{c}T_{\mathrm{A}} \\
(\mathrm{K}) \\
\end{array}$} & \multirow{2}{*}{$\begin{array}{c}\text { Amount } \\
\text { (cm) }\end{array}$} & $\delta^{18} \mathbf{O}_{v}$ & $\delta^{2} \mathbf{H}_{v}$ \\
\hline & & & & & \multicolumn{2}{|c|}{$(\%)$} \\
\hline $\begin{array}{l}26 \text { Jul } 88 \\
28 \text { Jul } 88 \\
20 \text { Sep } 88 \\
12 \text { Oct } 88 \\
14 \text { Nov } 88 \\
17 \text { Nov } 88 \\
23 \text { Nov } 88\end{array}$ & $\begin{array}{r}-2.95 \\
-7.75 \\
-8.85 \\
-6.65 \\
-8.05 \\
-8.75 \\
-13.50\end{array}$ & $\begin{array}{r}-29.0 \\
-60.0 \\
-74.0 \\
-53.0 \\
-57.5 \\
-60.5 \\
-105.5\end{array}$ & $\begin{array}{l}307.6 \\
305.4 \\
298.2 \\
292.0 \\
286.0 \\
285.4 \\
288.8\end{array}$ & $\begin{array}{l}0.30 \\
0.18 \\
0.15 \\
0.17 \\
0.19 \\
0.32 \\
1.15\end{array}$ & $\begin{array}{l}-11.6 \\
-16.6 \\
-18.3 \\
-16.6 \\
-18.5 \\
-19.3 \\
-23.7\end{array}$ & $\begin{array}{r}-98.6 \\
-131.8 \\
-153.3 \\
-139.3 \\
-151.5 \\
-155.2 \\
-195.9\end{array}$ \\
\hline $\begin{array}{r}29 \text { May } 89 \\
5 \text { Jun } 89 \\
27 \text { Jun } 89 \\
8 \text { Aug } 89 \\
9 \text { Aug } 89 \\
17 \text { Sep } 89 \\
19 \text { Scp } 89 \\
29 \text { Sep } 89 \\
30 \text { Sep } 89 \\
2 \text { Oct } 89 \\
3 \text { Oct } 89\end{array}$ & $\begin{array}{r}-15.00 \\
-14.20 \\
-2.00 \\
-7.05 \\
-9.45 \\
-15.65 \\
-10.30 \\
-11.40 \\
-8.70 \\
-13.35 \\
-9.80\end{array}$ & $\begin{array}{r}-111.0 \\
-112.5 \\
-36.5 \\
-54.5 \\
-62.5 \\
-117.5 \\
-78.0 \\
-85.5 \\
-67.5 \\
-98.5 \\
-75.0\end{array}$ & $\begin{array}{l}288.8 \\
293.8 \\
302.0 \\
296.4 \\
295.3 \\
299.4 \\
290.4 \\
297.0 \\
291.0 \\
293.2 \\
283.8\end{array}$ & $\begin{array}{l}0.24 \\
0.15 \\
0.51 \\
1.32 \\
0.81 \\
1.93 \\
0.46 \\
0.23 \\
0.10 \\
0.23 \\
1.11\end{array}$ & $\begin{array}{l}-25.2 \\
-24.0 \\
-11.1 \\
-16.6 \\
-19.1 \\
-25.0 \\
-20.4 \\
-20.9 \\
-18.7 \\
-23.2 \\
-20.5\end{array}$ & $\begin{array}{l}-201.4 \\
-196.9 \\
-111.7 \\
-111.7 \\
-145.0 \\
-195.6 \\
-166.4 \\
-166.1 \\
-155.2 \\
-183.5 \\
-171.9\end{array}$ \\
\hline
\end{tabular}

able for condensation. After a thick rind of frost formed on exposed surfaces of the copper tubing, a vacuum pump was used to draw air through the traps. This technique ensured complete removal of the vapor by the first trap in 38 of 41 experiments. Data from the three experiments that produced water in the second trap were discarded.

Vapor-phase extractions were made at the Deepsite raft and at the Northshore and Southshore sites during times when the wind was blowing from the lake to these sites. Isotopic data from these experiments are therefore representative of the isotopic content of air existing in the mixed layer above the lake surface. Vapor-phase extractions at the Sutcliffe site were made under variable wind conditions. Moisture from these samples represented a mixture of lake-derived and advected sources.

Precipitation samples (Table 1) were collected in an 8-cm-diameter cylinder at Sutcliffe during the warm seasons of 1988 and 1989. The samples were collected the morning after precipitation. Samples from rains in excess of $0.1 \mathrm{~cm}$ were analyzed to eliminate the effects of in-can and below-cloud evaporation on the isotopic composition of precipitation samples (Benson and Klieforth 1989). Lake-water samples were collected from the upper $1 \mathrm{~cm}$ of lake water within $\sim 5 \mathrm{~m}$ of the inlet of the vaporextraction apparatus.
A series of paired extractions made at different flow rates indicated that all water vapor that entered the extraction apparatus was collected in the first trap (samples $080388 \mathrm{a}, \mathrm{b}, \mathrm{c}, \mathrm{d}$ and 061289a,b,c,d; Table 2). The $\delta^{18} \mathrm{O}$ and $\delta^{2} \mathrm{H}$ values of the paired samples differed by $0.3-$ 0.7 and by $3-9 \%$. These differences are attributed to extraction error (combined with analytical error).

Inlet height (distance above lake surface) was varied in six paired extractions (Table 2). In four of the extractions (102088a and b, 090688a and $b, 061389 a$ and $b$, and 090788a and b), the $\delta^{18} \mathrm{O}$ value of water vapor extracted from the lower inlet was heavier by more than $0.9-$ $1.3 \%$, and the $\delta^{2} \mathrm{H}$ value was heavier by $6-$ $11 \%$. This indicates that relatively dry advected air has mixed with lake-derived moisture at some distance $(<2 \mathrm{~m})$ above the surface of the lake. The amount of sample produced in the extractions was proportional to flow rate.

Isotopic analyses were performed under the supervision of Carol Kendall and Tyler Coplen, using a $\mathrm{CO}_{2}$ equilibration technique for ${ }^{18} \mathrm{O}$ and a hydrogen equilibration technique for ${ }^{2} \mathrm{H}$. The oxygen- and hydrogen-isotope results are reported in per mil (\%) relative to VSMOW (Vienna Standard Mean Ocean Water). The 2- $\sigma$ precision of the oxygen and hydrogen results is respectively 0.2 and $2.0 \%$.

Water temperature measurements were 


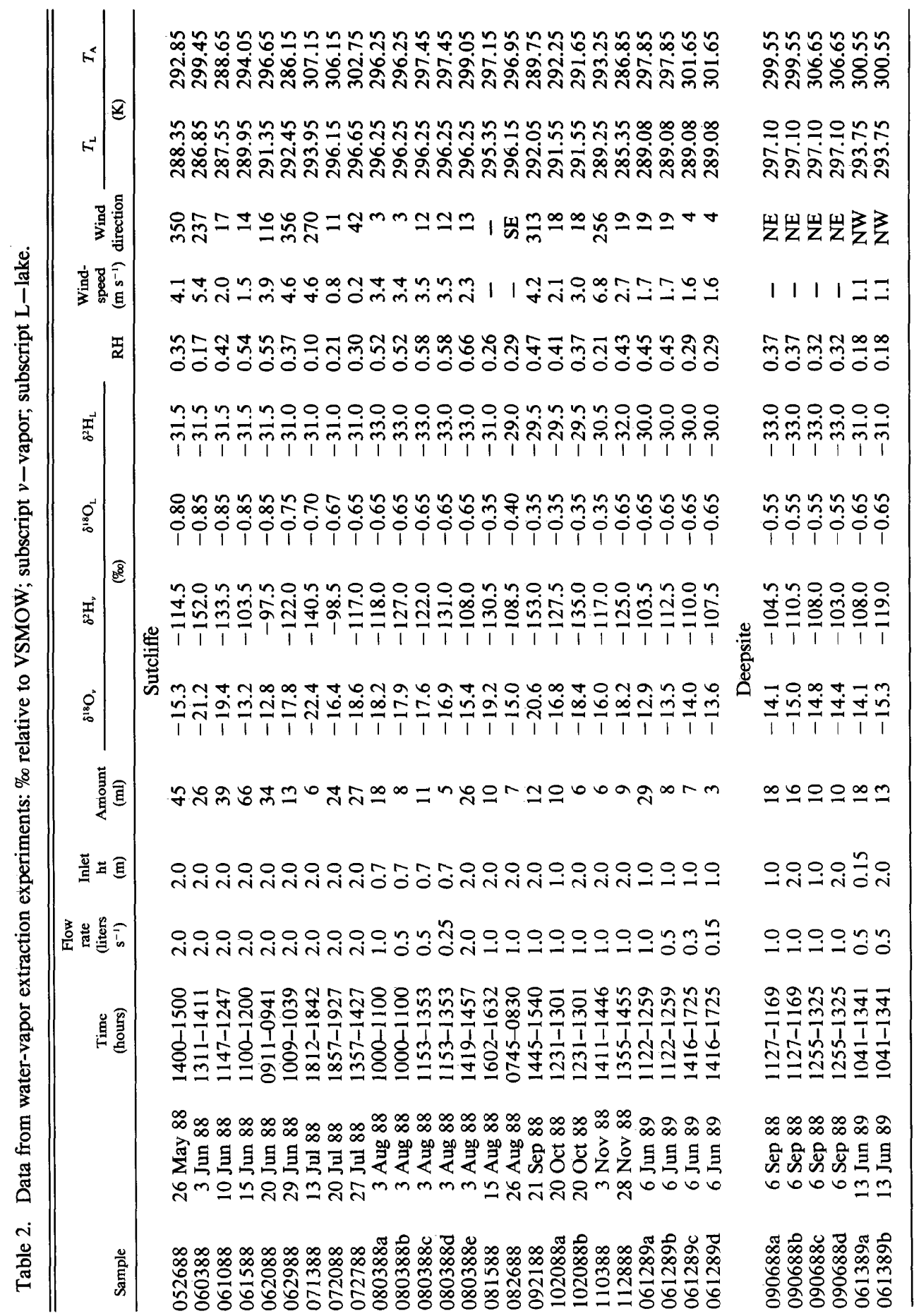




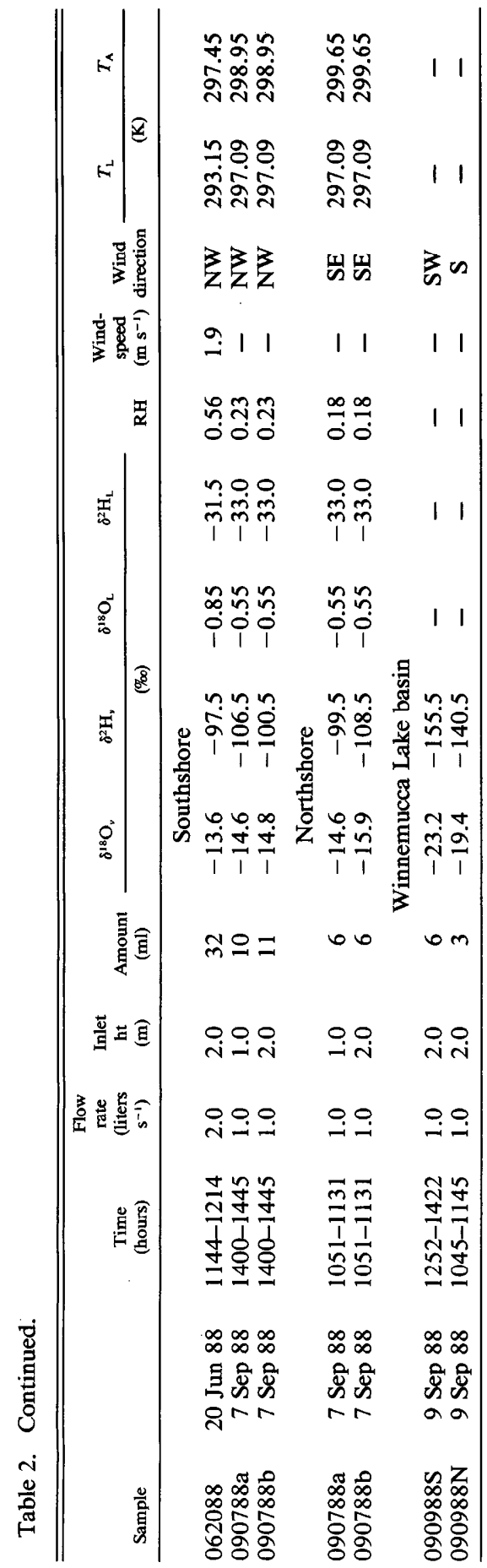

made at the time of vapor extraction. Data on air temperature, relative humidity, and wind direction and speed were available from a weather station located within $50 \mathrm{~m}$ of the Sutcliffe site. Data from this site were recorded every 15 min (Hostetler and Benson 1993). Weather stations at the other three sites that border Pyramid Lake were only intermittently operated.

\section{Results}

The influence of wind direction on the stableisotope value of extracted water vapor-Isotopic measurements were made at the Deepsite raft and at the Northshore and Southshore sites when the wind was blowing across the water to the site (onshore wind). These measurements have relatively heavy $\delta^{18} \mathrm{O}$ values ranging from -13.6 to $-15.9 \%$, and heavy $\delta^{2} \mathrm{H}$ values, ranging from -97.5 to $-119.0 \%$ (Table 2). These measurements are considered representative of moisture contained in the mixed layer that overlies the lake. During times of onshore winds at the Sutcliffe site (which occur when the vector wind lies in the $165^{\circ}$ sector between 330 and $135^{\circ}$ ), values of $\delta^{18} \mathrm{O}$ and $\delta^{2} \mathrm{H}$ were highly variable, ranging from -12.8 to $-18.6 \%$ and from -103.5 to $-135.0 \%$ (Table 2). The high degree of isotopic variability at this site probably indicates mixing of isotopically light advected moisture with isotopically heavy lake-derived moisture (i.e. many of the air parcels that reach this site have complicated trajectories that pass over both land and lake surfaces before reaching the extraction site).

The three isotopically lightest samples extracted at the Sutcliffe site $(060388,071388$, and 092188 , Table 2) were obtained when the wind was blowing strongly from the land to the site (offshore wind) and probably represent the isotopic content of advected moisture. Isotopic measurements of relatively dry air from the Winnemucca (Dry) Lake basin also are isotopically light, with $\delta^{18} \mathrm{O}$ values of -19.4 and $-23.2 \%$ and $\delta^{2} \mathrm{H}$ values of -140.5 and $-155.5 \%$. These values are also considered representative of advected moisture.

Isotopic content of the liquid and vapor phases and their relation to the mean global meteoric waterline (GMWL)-Isotopic data from the Sutcliffe site (Tables 1 and 2) have been used to illustrate the positions of the liquid and va- 


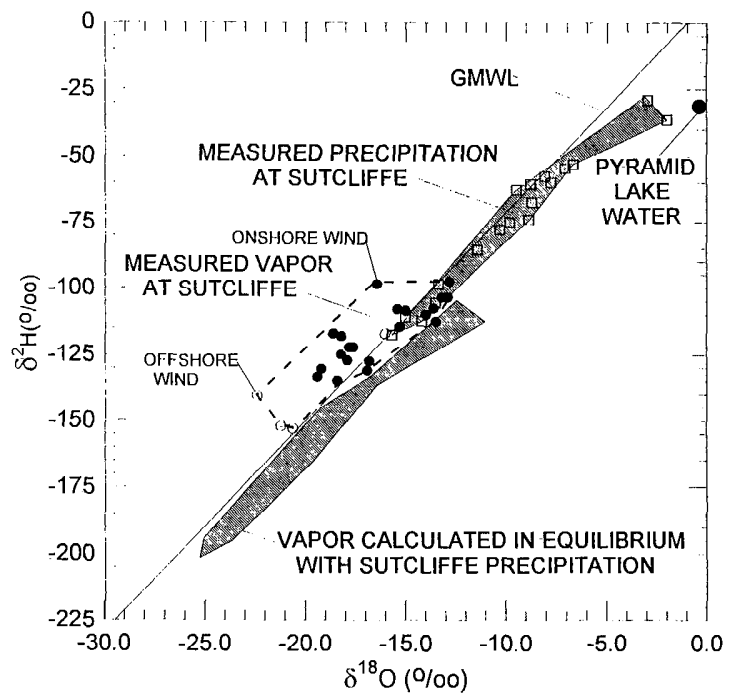

Fig. 3. Plot of stable isotope content of Sutcliffe precipitation $(\square)$, vapor phase calculated to exist in cquilibrium with Sutcliffe precipitation, and water vapor extracted from the air at Sutcliffe $(\mathrm{O}$-offshore wind conditions; - onshore wind conditions) relative to position of the mean global meteoric water line (GMWL).

por phases relative to the position of the GMWL in $\delta^{18} \mathrm{O}-\delta^{2} \mathrm{H}$ space (Fig. 3). The isotopic content of precipitation at Sutcliffe falls on or immediately below the GMWL, while isotopic values of the vapor phase in equilibrium with Sutcliffe precipitation (calculated with the equations of Majoube 1971) also plot on and below the GMWL but are shifted to lighter values than the liquid phase (Fig. 3). Isotopic values of vapor extracted at the Sutcliffe site plot on and above the GMWL, and they also plot above isotopic values of the vapor phase in equilibrium with Sutcliffe precipitation. The location of the extracted vapor in $\delta^{18} \mathrm{O}-\delta^{2} \mathrm{H}$ space is highly unusual relative to the position of the GMWL and indicates the presence of evaporated moisture. Isotopic values of vapor extracted at the Northshore, Southshore, and Deepsite raft sites (Table 2) also fall on or above the GMWL and are heavy relative to the vapor phase associated with precipitation events at Sutcliffe.

\section{Discussion}

The three isotopically light measurements obtained when a strong offshore wind was blowing at the Sutcliffe site and the two isotopic measurements of relatively dry air from the Winnemucca (Dry) Lake basin allow us to estimate that $\delta^{18} \mathrm{O}$ and $\delta^{2} \mathrm{H}$ values of water vapor in advected air are $\sim-21$ and $\sim-158 \%$. The value used for $\delta^{2} \mathrm{H}$ was calculated with the equation for GMWL and a $\delta^{18} \mathrm{O}$ value of $-21 \%$. It is slightly more negative than measured values. The 11 extractions from the Deepsite, Southshore, and Northshore sites indicate that $\delta^{18} \mathrm{O}$ and $\delta^{2} \mathrm{H}$ values of mixed-layer moisture, which is at least partially derived from evaporation, average $\sim-14.5$ and $\sim-105 \%$ (Table 2 ). In the following discussion, isotope mass-balance calculations are derived and applied to the Pyramid Lake data to estimate the relative amounts of lake-derived (evaporated) and advected water vapor contained in moist air in the Pyramid Lake basin.

Derivation of the isotope mass-balanceIsotope mass-balance calculations were performed to estimate the relative amounts of evaporated and advected water contained in the extracts. The isotopic balance of a lake is given by

$$
\begin{aligned}
\frac{\partial(\delta V)}{\partial t}= & \left(P \delta_{p}-E \delta_{e}\right) A+S_{i} \delta S_{i}-S_{o} \delta S_{o} \\
& +G_{i} \delta G_{i}-G_{o} \delta G_{o} .
\end{aligned}
$$

$t$ is time, $V$ is lake volume, $\delta$ indicates either $\delta^{18} \mathrm{O}$ or $\delta^{2} \mathrm{H}, P$ is on-lake precipitation, $\delta_{p}$ is the isotopic composition of precipitation, $E$ is lake evaporation, $\delta_{e}$ is the isotopic composition of evaporated water, $A$ is the surface area of the lakc, $S_{i}$ is surface-water discharge to the lake, $\delta S_{i}$ is the isotopic composition of surfacewater discharge, $S_{o}$ is surface-water outflow, $\delta S_{o}$ is the isotopic composition of surface-water outflow, $G_{i}$ is groundwater discharge to the lake, $\delta G_{i}$ is the isotopic composition of groundwater discharge, $G_{o}$ is groundwater outflow, and $\delta G_{o}$ is the isotopic composition of groundwater outflow.

For a closed-basin lake in which groundwater flux across the sediment-water interface is negligible (such as Pyramid Lake, Benson 1994), Eq. 1 reduces to

$$
\frac{\partial(\delta V)}{\partial t}=\left(P \delta_{p}-E \delta_{e}\right) A+S_{i} \delta S_{i} .
$$

Ongoing studies of the isotopic evolution of Pyramid Lake have included measurement of $\delta V, P, \delta_{p}, \delta S_{i}, A, S_{i}$ (Benson 1994), and cal- 
culation of $E$ (Hostetler and Benson 1994). In this study $\delta_{v}$, the isotopic composition of vapor in the Pyramid Lake basin, was measured. The vapor consists of two components

$$
\delta_{v}=\delta_{e}+\delta_{a d} .
$$

$\delta_{a d}$ is the isotopic composition of water vapor advected into the Pyramid Lake basin ( $\delta_{a d}$ is equivalent to $\delta_{\text {atmospheric }}$ referred to in other studies).

In the following, we derive equations that allow calculation of $\delta_{e}$ from the data of Table 2 . Our derivation is based on the conceptual evaporation model first presented by Craig and Gordon (1965). Our derivation differs from their mathematical treatment in several ways. We deviate from their seminal work in formulating the basic set of equations that describe isotopic fractionation in terms of ratios of isotopic species, $R_{i}$. This allows simple conversion of laboratory values of $\delta_{i}$ to $R_{i}$, using

$$
\delta_{i}=\left(\frac{R_{i}}{R_{s t d}}-1\right) \times 10^{3}
$$

$R_{i}$ represents the isotopic ratio of a sample $\left({ }^{2} \mathrm{H}:{ }^{1} \mathrm{H},{ }^{18} \mathrm{O}:{ }^{16} \mathrm{O}\right)$, and $R_{\text {std }}$ is the corresponding isotopic ratio in a standard.

Our derivation includes an expression for $\boldsymbol{R}_{\boldsymbol{e}}$ (the isotopic ratio in evaporating moisture) in terms of the fractions of advected and lakederived moisture. This formulation allows us to perform an analysis of the sensitivity of $R_{c}$ to change in values of the following: the isotopic ratio of lake water, the isotopic ratio of advected air, the relative humidity of the mixed layer, the equilibrium and kinetic fractionation factors. In addition, the equilibrium and kinetic fractionation of isotopes are separately treated in our derivation, allowing us to use Merlivat and Jouzel's (1979) determinations of the dependence of kinetic fractionation factor on windspeeds. We also derive a net vapor flux, avoiding introduction of gross evaporation and back condensation fluxes, which are difficult if not impossible to measure.

In the Craig-Gordon model, vapor transport is dominated by molecular transfer across a theoretical laminar layer of thickness $z$. The base of the laminar layer is assumed virtually saturated with the relative humidity $\mathrm{RH}=$ $100 \%$. Equilibrium fractionation of oxygen and hydrogen isotopes occurs at the liquid-air in- terface, with the lighter isotopes being preferentially incorporated into the less-condensed vapor phase. Diffusion of the isotopic species across the laminar layer is a function of their concentrations (measured at the base of the turbulent layer) and their individual diffusivities. Above the laminar layer, a fully turbulent region is assumed to exist (the turbulent mixed layer) in which lake-derived water vapor mixes with water vapor derived from other intra- and extra-basinal sources.

The evaporative flux $(F)$ from the surface of a lake can be expressed by Fick's first law of diffusion:

$$
F=D \frac{\mathrm{d} c}{\mathrm{~d} z}
$$

$D$ is the diffusivity, $\mathrm{d} c / \mathrm{d} z$ the concentration gradient, and $\mathrm{d} z=z$ the laminar layer thickness. In terms of the oxygen species, bulk water is almost entirely composed of ${ }^{16} \mathrm{O}$; therefore, the diffusion of water $\left(\mathrm{H}_{2}{ }^{16} \mathrm{O}\right)$ across the laminar layer is given by

$$
F^{16}=\frac{D^{16}}{z}\left(c^{16}{ }_{s a t}-c^{16}{ }_{v}\right) .
$$

$c^{16}{ }_{\text {sat }}$ is the concentration of saturated air at the liquid-air interface, and $c^{16}{ }_{v}$ is the concentration of vapor at the base of the turbulent region. The derivations which are written in terms of the isotopic species of oxygen are wholly applicable to the isotopic species of hydrogen. Since RH is the ratio of vapor concentration in moist air to the concentration at saturation (i.e. $\mathrm{RH}=c^{16}{ }_{v} / c^{16}{ }_{\text {sat }}$ if and only if air temperature = vapor-saturated air temperature at the base of the laminar layer),

$$
F^{16}=\frac{D^{16}}{z}(1-\mathrm{RH}) \mathcal{C}^{16}{ }_{s a t} .
$$

The diffusive flux of the trace constituent $\mathrm{H}_{2}{ }^{18} \mathrm{O}$ is given by

$$
F^{18}=\frac{D^{18}}{z}\left(c^{18}{ }_{s a t}-c^{18}{ }_{v}\right) .
$$

$c^{18}{ }_{\text {sat }}$ is the concentration of ${ }^{18} \mathrm{O}$ in saturated air at the liquid-air interface, and $c^{18}{ }_{v}$ is the concentration of ${ }^{18} \mathrm{O}$ in vapor at the base of the turbulent region. The equilibrium fractionation factor $\alpha_{e q}$ is defined as 


$$
\alpha_{e q}=\frac{R_{L}}{R_{s a t}} .
$$

$R_{L}$ is the isotope ratio $\left({ }^{18} \mathrm{O}:{ }^{16} \mathrm{O},{ }^{2} \mathrm{H}:{ }^{1} \mathrm{H}\right)$ in the liquid undergoing evaporation, and $R_{s a t}$ is the isotope ratio in the saturated vapor at the base of the laminar layer. Written this way, $\alpha_{e q}$ $>1$. The concentration of ${ }^{18} \mathrm{O}$ in saturated air at the liquid-air interface $\left(c^{18}{ }_{\text {sat }}\right)$ is written

$$
c^{18}{ }_{\text {sat }}=\frac{R_{L}}{\alpha_{e q}} c^{16}{ }_{\text {sat }} .
$$

The concentration of ${ }^{18} \mathrm{O}$ in vapor at the base of the turbulent region $\left(C^{18}\right)$ is written

$$
c^{18}{ }_{\text {air }}=\mathrm{RH} R_{v} c^{16}{ }_{\text {sat }} \text {. }
$$

$R_{v}$ is the isotope ratio in water vapor at the base of the turbulent region. Substituting Eq. 10 and 11 into Eq. 8 yields

$$
F^{18}=\frac{D^{18}}{z}\left(\frac{R_{L}}{\alpha_{e q}}-\mathrm{RH} R_{v}\right) c^{16}{ }_{s a t} .
$$

By definition, the ratio of the isotopic fluxes is identical to the isotopic ratio of the evaporated water:

$$
R_{e}=\frac{F^{18}}{F^{16}}=\frac{F_{\mathrm{H}_{2}{ }^{18} \mathrm{O}}}{F_{\mathrm{H}_{2}{ }^{16} \mathrm{O}}} .
$$

Substituting Eq. 7 and 12 into Eq. 13 yields

$$
R_{e}=\alpha_{k i n}\left[\frac{\left(R_{L} / \alpha_{e q}\right)-\mathrm{RH} R_{v}}{1-\mathrm{RH}}\right]
$$

$\alpha_{k i n}$ is defined as the ratio of isotopic diffusivities $\left(D^{18}: D^{16}\right)$ in the laminar layer $\left(\alpha_{k i n}<1\right.$ in this definition). To render Eq. 14 applicable to isotopic measurements made relative to the VSMOW (Vienna standard mean ocean water) standard, we divide Eq. 14 by $R_{\text {vsmow }}$

$$
\begin{aligned}
& \frac{R_{e}}{R_{\mathrm{vSMOw}}} \\
& \quad=\alpha_{\text {kin }}\left[\frac{\left(R_{L} / R_{\mathrm{vSMOW}}\right) \alpha_{e q}-\mathrm{RH}\left(R_{v} / R_{\text {vSMOW }}\right)}{1-\mathrm{RH}}\right]
\end{aligned}
$$

and denote the standardized ratios in boldface; i.e.

$$
\boldsymbol{R}_{e}=\alpha_{k i n}\left(\frac{\boldsymbol{R}_{L} / \alpha_{e q}-\mathbf{R H}_{\boldsymbol{R}}}{1-\mathrm{RH}}\right)
$$

If the water vapor above the laminar layer is a mixture of lake-derived vapor and advected vapor,

$$
\boldsymbol{R}_{v}=\boldsymbol{R}_{e}+\boldsymbol{R}_{a d}
$$

Substituting Eq. 17 into 16 yields

$$
\begin{aligned}
\boldsymbol{R}_{e}= & \frac{\alpha_{k i n}}{1-\mathrm{RH}} \\
& \cdot\left\{\frac{\boldsymbol{R}_{L}}{\alpha_{e q}}-\mathrm{RH}\left[f_{a d} \boldsymbol{R}_{a d}+\left(1-f_{a d}\right) \boldsymbol{R}_{e}\right]\right\} .
\end{aligned}
$$

$\int_{a d}$ is the fraction of advected air. Rearranging Eq. 18 and solving for $\boldsymbol{R}_{e}$ yields

$$
\boldsymbol{R}_{e}=\frac{\frac{\boldsymbol{R}_{\boldsymbol{L}}}{\alpha_{e q}}-\mathrm{RH} f_{a d} \boldsymbol{R}_{a d}}{\left(\frac{1-\mathrm{RH}}{\alpha_{k i n}}\right)+\mathrm{RH}\left(1-f_{a d}\right)}
$$

If all the water vapor overlying the lake is advected, $f_{a d}=1$, and Eq. 18 becomes

$$
\boldsymbol{R}_{e}=\frac{\left(\alpha_{k i n} / \alpha_{e q}\right) \boldsymbol{R}_{L}-\alpha_{k i n} \mathrm{RH} \boldsymbol{R}_{a d}}{1-\mathrm{RH}} .
$$

If all the water vapor overlying the lake is derived by evaporation of lake water, $f_{a d}=0$, and Eq. 18 becomes

$$
\boldsymbol{R}_{e}=\boldsymbol{R}_{L} \frac{\alpha_{k i n}}{\alpha_{e q}}\left(\frac{1}{1-\mathrm{RH}+\mathrm{RH} \alpha_{k i n}}\right) .
$$

Laboratory values of $\delta$ were converted to the standardized ratios given in Eq. 18 and 19 with a standardized form of Eq. 4; i.e.

$$
\delta_{i}=\left(\boldsymbol{R}_{i}-1\right) \times 10^{3} .
$$

Values of $\alpha_{e q}$ can be calculated from the work of Majoube (1971):

$$
\begin{aligned}
\text { In } \alpha_{e q}\left({ }^{18} \mathrm{O}:{ }^{16} \mathrm{O}\right)= & 1,137 T_{\mathrm{L}}{ }^{-2}-0.4156 T_{\mathrm{L}}{ }^{-1} \\
& -2.0667 \times 10^{-3} \\
\text { In } \alpha_{e q}\left({ }^{2} \mathrm{H}:{ }^{1} \mathrm{H}\right)= & 24,844 T_{\mathrm{L}}{ }^{-2}-76.248 T_{\mathrm{L}}{ }^{-1} \\
& +52.612 \times 10^{-3}
\end{aligned}
$$

( $T_{\mathrm{L}}$ is in $\left.\mathrm{K}\right)$. Values of $\alpha_{k i n}$ have been calculated by Merlivat and Jouzel (1979). For the wind regime under which the vapor-extraction experiments were conducted, $\alpha_{k i n}\left({ }^{18} \mathrm{O}:{ }^{16} \mathrm{O}\right)=$ 0.994 and $\alpha_{k i n}\left({ }^{2} \mathrm{H}:{ }^{1} \mathrm{H}\right)=0.995$. 


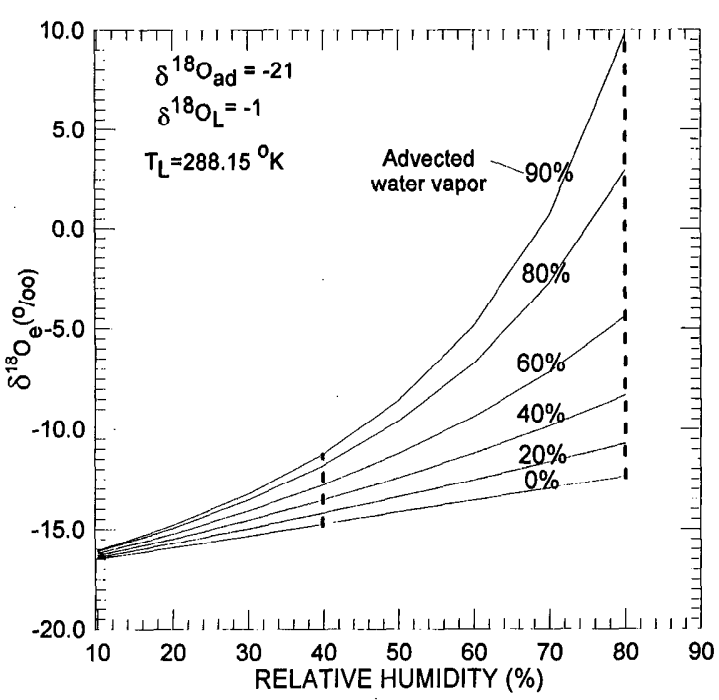

Fig. 4. The $\delta^{18} \mathrm{O}$ value of evaporated water as a function of relative humidity and amount of advected water vapor. Vertical dashed lines indicate relative humidities of 40 and $80 \%$. At $<40 \% \mathrm{RH}$, there is a $<0.04 \%$ increase in $\delta^{18} \mathrm{O}_{e}$ per percent increase in advected water vapor. At $80 \% \mathrm{RH}, \delta^{18} \mathrm{O}_{e}$ increases $0.25 \%$ per percent increase in advected water vapor.

The above equations can be used to calculate the composition of water evaporating from Pyramid Lake from the data listed in Table 2. Before the results of such calculations are presented, we first assess the effects of variation of $T_{\mathrm{L}}, f_{a d}, \mathrm{RH}$, and $\delta_{a d}$ on $\delta_{c}$.

Sensitivity tests-Sensitivity tests were run with Eq. 19 to determine the effects of variation of $T_{\mathrm{L}}, f_{a d}, \mathrm{RH}$, and $\delta_{a d}$ on $\delta_{e}$. Only the results for $\delta^{18} \mathrm{O}_{e}$ are illustrated (Figs. 4 and 5). During the season of high evaporation (JuneOctober, Fig. 2), surface-water temperature changes by $\sim 10 \mathrm{~K}$ (Hostetler and Benson 1990, 1993). The change in $\delta^{18} \mathrm{O}_{e}$ with surface-water temperature $\left(T_{\mathrm{L}}\right)$ is minimal - on the order of $0.1 \% 0 \mathrm{~K}^{-1}$; therefore, $\delta^{18} \mathrm{O}_{e}$ undergoes a $1.0 \%$ variation in $\delta^{18} \mathrm{O}_{e}$ between June and October, with heaviest values in August and September.

Change in $\delta^{18} \mathrm{O}_{e}$ as a function of $f_{a d}$ is modest at low humidities (Fig. 4). Below $\sim 40 \% \mathrm{RH}$, there is a $<0.04 \%$ increase in $\delta^{18} \mathrm{O}_{e}$ per percent increase in advected water vapor. With increasing humidity, the change in $\delta^{18} \mathrm{O}_{e}$ becomes large (e.g. see Fig. 4).

When $f_{a d}$ is large and when $\delta^{18} \mathrm{O}_{a d}$ is light relative to $\delta^{18} \mathrm{O}_{\mathrm{L}}, \delta^{18} \mathrm{O}_{e}$ changes rapidly with RH. For example, with $f_{a d}=0$ (all moisture is

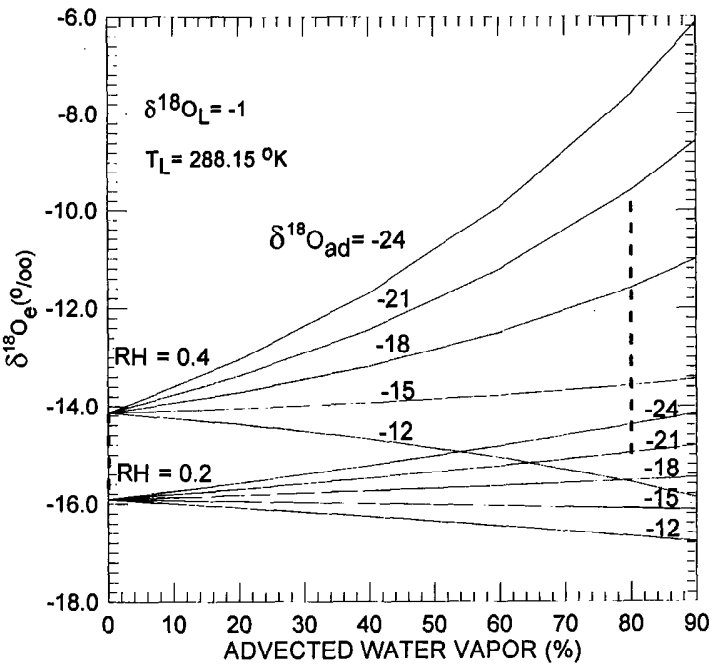

Fig. 5. The $\delta^{18} \mathrm{O}$ value of evaporated water as a function of the $\delta^{18} \mathrm{O}$ value and amount of advected water vapor. $\delta^{18} \mathrm{O}_{e}$ increases rapidly with increasing relative humidity when the percentage of advected water is large and when the $\delta^{18} \mathrm{O}_{a d}\left({ }^{18} \mathrm{O}\right.$ value of advected air) is very low. Vertical dashed lines indicate 0 and $80 \%$ regions of advected water vapor that arc discussed in the text.

derived from lake evaporation), $\delta^{18} \mathrm{O}_{e}$ increases $0.09 \%$ with each percent increase in $\mathrm{RH}$, but with $f_{a d}=80 \%$ and $\delta^{18} \mathrm{O}_{a d}=-21, \delta^{18} \mathrm{O}_{e}$ increases $0.26 \%$ with each percent increase in RH (Fig. 5). The $\delta^{18} \mathrm{O}$ of advected moisture in the Pyramid Lake basin is $\sim 21 \%$ and the mean daily $\mathrm{RH}$ ranges from $\sim 20$ to $\sim 80 \%$ during the evaporation season (Hostetler and Benson 1993); thus the value of $\delta^{18} \mathrm{O}_{e}$ is sensitive to variation in $f_{a d}$ when the advected air contains a lot of moisture.

In summary, $\delta^{18} \mathrm{O}_{e}$ becomes heavier with increasing $T_{\mathrm{L}}, f_{a d}$, and $\mathrm{RH}$ (if $\delta^{18} \mathrm{O}_{v}$ is lighter than $\delta^{18} \mathrm{O}_{e}$ ), indicating that the $\delta^{18} \mathrm{O}$ of evaporating moisture formed when $f_{a d}>0$ will be heavier relative to the $\delta^{18} \mathrm{O}$ of moisture evaporated into a mixed layer that is solely lake derived. This observation was previously made by Craig and Gordon (1965) for the world ocean.

Source of moisture in the mixed layer, isotopic calculations-Equation 19 was used to determine $\delta_{e}$ as a function of $f_{a d}$ using values of ratios of $0.979\left(\delta^{18} \mathrm{O}=-21\right)$ and $0.842\left(\delta^{2} \mathrm{H}\right.$ $=-158 \%$ ) for $\boldsymbol{R}_{a d}\left({ }^{18} \mathrm{O}:{ }^{16} \mathrm{O}\right)$ and $\boldsymbol{R}_{a d}\left({ }^{2} \mathrm{H}:{ }^{1} \mathrm{H}\right)$ (Table 3). No correction for nonideal behavior of liquid water has been made, as the thermodynamic activity of Pyramid Lake water is 
Table 3. Values of $\delta^{18} \mathrm{O}_{e}$ and $\delta^{2} \mathrm{H}_{e}(\%)$ calculated as a function of different percentages of advected air. Basic data used in the calculation taken from Table 1. Isotopic values of advected air are $\delta^{18} \mathrm{O}=-21, \delta^{2} \mathrm{H}=-158$.

\begin{tabular}{|c|c|c|c|c|c|c|c|c|}
\hline \multirow[b]{3}{*}{ Sample } & & & \multicolumn{6}{|c|}{$\%$ Advected air } \\
\hline & \multicolumn{2}{|c|}{ Measured (\%o) } & 0 & 20 & 40 & 0 & 20 & 40 \\
\hline & $\delta^{18} \mathrm{O}_{r}$ & $\delta^{2} \mathrm{H}_{v}$ & \multicolumn{3}{|c|}{$\delta^{18} \mathrm{O}_{\sigma}$} & \multicolumn{3}{|c|}{$\delta^{2} \mathrm{H}_{e}$} \\
\hline \multicolumn{9}{|c|}{ Sutcliffe } \\
\hline 052688 & -15.3 & -114.5 & -14.8 & -14.3 & -13.8 & -115.2 & -111.9 & -108.0 \\
\hline 060388 & -21.2 & -152.0 & -16.0 & -15.8 & -15.7 & -117.6 & -116.2 & -114.6 \\
\hline 061088 & -19.4 & -133.5 & -14.5 & -13.9 & -13.2 & -115.7 & -111.7 & -106.8 \\
\hline 061588 & -13.2 & -103.5 & -13.6 & -12.7 & -11.5 & -112.7 & -107.0 & -99.8 \\
\hline 062088 & -12.8 & -97.5 & -13.4 & -12.4 & -11.2 & -111.3 & -105.3 & -97.6 \\
\hline 062988 & -17.8 & -122.0 & -14.2 & -13.7 & -13.1 & -110.6 & -106.7 & -102.1 \\
\hline 071388 & -22.4 & -140.5 & -15.7 & -15.6 & -15.5 & -110.5 & -109.5 & -108.5 \\
\hline 072088 & -16.4 & -98.5 & -14.8 & -14.5 & -14.2 & -107.8 & -105.6 & -103.1 \\
\hline 072788 & -18.6 & -117.0 & -14.2 & -13.8 & -13.3 & -106.9 & -103.6 & -99.7 \\
\hline $080388 a$ & -18.2 & -118.0 & -12.9 & -12.0 & -10.8 & -108.1 & -102.1 & -94.5 \\
\hline $080388 b$ & -17.9 & -127.0 & -12.9 & -12.0 & -10.8 & -108.1 & -102.1 & -94.5 \\
\hline $080388 \mathrm{c}$ & -17.6 & -122.0 & -12.6 & -11.5 & -10.1 & -107.8 & -101.0 & -92.1 \\
\hline $080388 d$ & -16.9 & -131.0 & -12.6 & -11.5 & -10.1 & -107.8 & -101.0 & -92.1 \\
\hline $080388 \mathrm{e}$ & -15.4 & -108.0 & -12.1 & -10.8 & -8.9 & -107.5 & -99.5 & -88.7 \\
\hline 081588 & -19.2 & -130.5 & -14.3 & -13.9 & -13.5 & -108.3 & -105.5 & -102.4 \\
\hline 082688 & -15.0 & -108.5 & -14.1 & -13.6 & -13.2 & -105.6 & -102.3 & -98.5 \\
\hline 092188 & -20.6 & -153.0 & -13.3 & -12.5 & -11.5 & -109.1 & -103.9 & -97.4 \\
\hline $102088 a$ & -16.8 & -127.5 & -13.9 & -13.4 & -12.7 & -110.1 & -106.1 & -101.5 \\
\hline $102088 b$ & -18.4 & -135.0 & -13.7 & -13.0 & -12.3 & -109.9 & -105.5 & -100.1 \\
\hline 110388 & -16.0 & -117.0 & -15.1 & -14.8 & -14.5 & -114.1 & -112.1 & -109.9 \\
\hline 112888 & -18.2 & -125.0 & -14.4 & -13.8 & -13.1 & -118.5 & -114.6 & -109.9 \\
\hline $061289 a$ & -12.9 & -103.5 & -14.0 & -13.3 & -12.4 & -112.7 & -108.0 & -102.3 \\
\hline $061289 \mathrm{~b}$ & -13.5 & -112.5 & -14.0 & -13.3 & -12.4 & -112.7 & -108.0 & -102.3 \\
\hline $061289 \mathrm{c}$ & -14.0 & -110.0 & -14.9 & -14.5 & -14.1 & -113.4 & -110.6 & -107.3 \\
\hline $061289 d$ & -13.6 & -107.5 & -14.9 & -14.5 & -14.1 & -113.4 & -110.6 & -107.3 \\
\hline \multicolumn{9}{|c|}{ Deepsite } \\
\hline $090688 \mathbf{a}$ & -14.1 & -104.5 & -13.7 & -13.1 & -12.4 & -108.0 & -103.9 & -99.1 \\
\hline $090688 b$ & -15.0 & -110.5 & -13.7 & -13.1 & -12.4 & -108.0 & -103.9 & -99.1 \\
\hline $090688 \mathrm{c}$ & -14.8 & -108.5 & -14.0 & -13.5 & -12.9 & -108.3 & -104.8 & -100.7 \\
\hline $090688 d$ & -14.4 & -103.0 & -14.0 & $-13: 5$ & -12.9 & -108.3 & -104.8 & -100.7 \\
\hline $061389 a$ & -14.1 & -108.0 & -15.2 & -14.9 & -14.7 & -110.2 & -108.4 & -106.4 \\
\hline $061389 \mathrm{~b}$ & -15.3 & -119.0 & -15.2 & -14.9 & -14.7 & -110.2 & -108.4 & -106.4 \\
\hline \multicolumn{9}{|c|}{ Southshore } \\
\hline 062088 & -13.6 & -97.5 & -13.2 & -12.2 & -10.9 & -109.5 & -103.1 & -94.9 \\
\hline $090788 \mathrm{a}$ & -14.6 & -106.5 & -14.5 & -14.2 & -13.8 & -108.7 & -106.3 & -103.5 \\
\hline $090788 b$ & -14.8 & -100.5 & -14.5 & -14.2 & -13.8 & -108.7 & -106.3 & -103.5 \\
\hline \multicolumn{9}{|c|}{ Northshore } \\
\hline $090788 a$ & -14.6 & -99.5 & -14.8 & -14.6 & -14.3 & -109.0 & -107.1 & -105.0 \\
\hline $090788 b$ & -15.9 & -108.5 & -14.8 & -14.6 & -14.3 & -109.0 & -107.1 & -105.0 \\
\hline
\end{tabular}

0.997. In the case in which all moisture overlying a lake is derived by evaporation, the isotopic value of moisture extracted from the mixed layer $\left(\delta_{v}\right)$ is identical to the isotopic value of evaporated moisture $\left(\delta_{e}\right)$ at the laminar mixed-layer boundary.

Data from vapor-phase extractions made when the wind was blowing from the lake to the Deepsite, Southshore, and Northshore sites indicate that 7 of 11 measurements of $\delta^{18} \mathrm{O}_{v}$ and 6 of 11 measurements of $\delta^{2} \mathbf{H}_{v}$ are within
0.4 and $4.0 \%$ (the combined analytical error) of values calculated assuming that $f_{a d}=0$ (Table 3). These measurements are consistent with the hypothesis that moisture immediately above the laminar layer is totally lake derived.

Differences in measured and calculated $\delta^{2} \mathrm{H}$ values $(5.3-9.5 \%)$ for the other four samples are within the range of extraction error (3.09.0\%); however, differences in measured and calculated $\delta^{18} \mathrm{O}$ values $(0.8-1.3 \%)$ are outside the range of extraction error $(0.3-0.7 \%)$. Val- 
ues of $\delta^{18} \mathrm{O}_{v}$ in three (090688b,c, and 061389a) of the four samples are isotopically lighter than values calculated assuming that $f_{a d}=0$ (Table 3). Given that 10 of 11 measured $\delta^{18} \mathrm{O}_{v}$ samples were the same as or isotopically lighter than calculated values of $\delta^{18} \mathrm{O}_{v}$ (that assumed $f_{a d}=$ 0 ), the entire data set is consistent with the hypothesis that moisture immediately above the laminar layer is totally lake derived but that advected air mixes down into lake-derived moisture some distance above the lake surface. These data, however, do not exclude the possibility that advected air mixes down to the surface of the laminar layer $\left(f_{a d}>0\right)$ and that the isotopically heavy vapor formed during evaporation acquires an increasingly greater proportion of advected air as a function of distance above the lake surface. The isotopic value of vapor formed when $f_{a d}>0$ is always enriched relative to the isotopic value of vapor formed when $f_{a d}=0$ (see Table 3).

The $\delta^{18} \mathrm{O}$ values of 18 of 25 vapor samples and the $\delta^{2} \mathrm{H}$ values of 13 of 25 vapor samples extracted at the Sutcliffe site are statistically lighter $\left(\delta^{18} \mathrm{O}\right.$ and $\delta^{2} \mathrm{H}$ differences $>0.7$ and $>9.0 \%$ ) relative to values calculated assuming that $f_{a d}=0$ (Table 3). Three $\delta^{18} \mathrm{O}_{v}(061289 \mathrm{a}, \mathrm{c}, \mathrm{d})$ and three $\delta^{2} \mathbf{H}_{v}(060288,072088,061289 a)$ samples from the Sutcliffe site are statistically heavier than values calculated assuming that $f_{a d}=0$. Four $\delta^{18} \mathrm{O}_{v}$ samples $(052688,061588$, $062088,061289 \mathrm{~b}$ ) and nine $\delta^{2} \mathrm{H}_{v}$ samples $(052688,061588,080388 \mathrm{e}, 082688,110388$, $061289 a, b, c, d)$ from the Sutcliffe site are not statistically different from values calculated assuming that $f_{a d}=0$.

The large number of isotopically light values of $\delta_{v}$ obtained at the Sutcliffe site indicates the possibility that many of these samples represent a mechanical mixture of isotopically light advected moisture and isotopically heavy evaporated moisture (Fig. 6). Samples from the Sutcliffe, Deepsite, Southshore, and Northshore sites with $\delta^{18} \mathrm{O}_{v}$ values heavier than $-15.5 \%$ and $\delta^{2} \mathbf{H}_{v}$ values heavier than $-120.0 \%$ probably represent evaporation into a well-mixed layer that contained $\leq 40 \%$ advected air (Fig. 6).

Several of these samples $(062088,072088$, 061289a, 090688a,d, SS062088, SS090788b, NS09078a) which plot in the $40 \%$ advected region of Fig. 6 would plot inside of the $100 \%$ lake-derived region if their $\delta^{2} \mathbf{H}_{v}$ values were

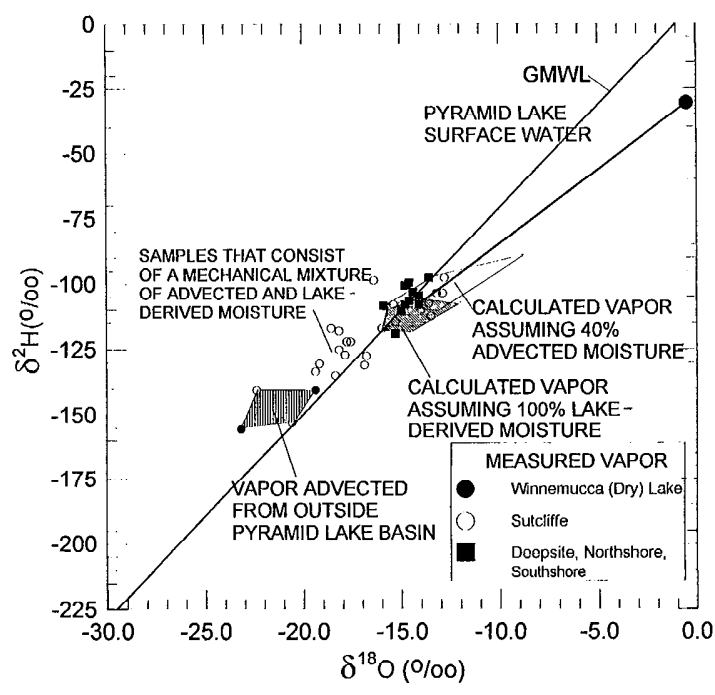

Fig. 6. Stable isotope values of water vapor extracted from the mixed layer at the Sutcliffe site, from the Deepsite, Northshore, and Southshore sites when the wind was blowing from the lake to the site, and from Winnemucca (Dry) Lake plotted relative to the position of the GMWL. The advected vapor region is based on isotopically light valucs of vapor extracted from the Sutcliffe and Winnemucca sites (Fig. 1). Theoretical isotopic values of $\delta_{v}$ are shown for evaporation into a mixed layer above Pyramid Lake containing 0 and $40 \%$ advected air.

decreased by $\leq 10 \%$. Because the extraction error with respect to $\delta^{2} \mathbf{H}_{v}$ was $\leq 9 \%$, it is possible that all samples with $\delta^{18} \mathrm{O}_{v}$ values heavier than $-15.5 \%$ were completely lake derived.

Source of moisture in the mixed layer, material mass-balance calculations - The relative amount of lake-derived moisture found in the mixed layer can also be approximated by subtracting the mass of water in advected air from the mass of water in the mixed layer. Data from a weather station located on the west side of Reno (Royal Drive, Fig. 1) were used to approximate the water-vapor content of relatively dry air that enters the Pyramid Lake basin.

The mass of water in a unit volume of air can be calculated from measured values of RH. $T_{\mathrm{A}}$, and barometric $(p)$. The mixing ratio, $r$, is defined as

$$
r=\frac{m_{v}}{m_{d}}
$$

$m_{v}$ is the mass of water vapor, and $m_{d}$ is the mass of dry air in a given volume of moist air 
(List 1984). Values of $r$ can be approximated (Sutton 1977) with

$$
r=0.62197 \frac{e_{v}}{p-e_{v}} .
$$

0.62197 is the ratio of the molecular weight of water vapor to the apparent molecular weight of dry air, $e_{v}$ is water-vapor pressure, and $p$ is the total air pressure $(\mathrm{mb})$. Water-vapor pressure of ambient air can be calculated from

$$
e_{v}=\mathrm{RH} e_{v s} .
$$

$e_{v s}$ is the vapor pressure of saturated air. The saturated vapor pressure can be calculated (Richards 1971) with $e_{v s}=1,013.25$ $\exp \left(13.3185 T_{r}-1.9760 T_{r}{ }^{2}-0.6445 T_{r}^{3}-\right.$ $\left.0.1299 T_{r}^{4}\right)$, where $T_{r}=1-\left(373.15 / T_{\mathrm{A}}\right)$. The concentration of water vapor in moist air, known as the absolute humidity, $\mathrm{AH}$, is defined as

$$
\mathrm{AH}=\frac{m_{v}}{V_{\text {mix }}} .
$$

$m_{v}$ is the mass of water vapor contained in the volume of mixture, $V_{\text {mix }}$. Substituting Eq. 24 and 25 into Eq. 26 and using the definition $\rho_{v}=\mathrm{AH}$ gives

$$
\mathrm{AH}=\rho_{v}=0.62197 \times \frac{\mathrm{RH} e_{v s}}{p-\left(\mathrm{RH} e_{v s}\right)} \rho_{d}
$$

where, $\rho_{d}$, the dry air density, is equal to

$$
\rho_{d}=0.34838 \frac{p}{C T_{\mathrm{v}}}
$$

and where the compressibility factor, $C$, equals 0.9997 over the range of meteorological conditions occurring during the vapor-phase extractions. At Reno, the mean atmospheric pressure is $865 \mathrm{mb}$, and at Pyramid Lake it is $895 \mathrm{mb}$. The virtual temperature $\left(T_{\mathrm{v}}\right)$ can be caluculated from

$$
T_{\mathrm{v}}=T_{\mathrm{A}} \frac{1+r / 0.62197}{1+r} .
$$

Equations 27-29 were used to calculate concentrations of water vapor in moist air at Reno and Pyramid Lake for times of water-vapor extraction. Recognizing the approximate nature of these calculations (e.g. the wind did not always blow from Reno to Pyramid Lake on the day of the isotopic measurement), the results (Table 4) indicate that moisture derived from Pyramid Lake evaporation usually accounts for $50-80 \%$ of the water vapor produced in the extraction experiments. The four Sutcliffe samples extracted during westerly (advective) winds contained, respectively, 32, 12,42 , and $0 \%$ lake-derived moisture (Table 4). Samples extracted at the Deepsite and the Southshore sites contained between 65 and $80 \%$ lake-derived moisture.

Calculations also indicate that three samples of Sutcliffe air contained less moisture than Reno air (Table 4). The first sample was extracted during a time of precipitation (Table 1), and condensation may have reduced the amount of moisture reaching the lake. However, it did not rain on the two other days, and the simplest explanation for this physically improbable decrease in moisture is that the air parcels entered the lake basin from another direction. This explanation also can account for the small amount of lake-derived moisture calculated to exist in two samples extracted from the Northshore site (Tables 3 and 4).

\section{Implications for other studies}

The data and arguments presented in this paper support the hypothesis that most and possibly all moisture that overlies the surface of Pyramid Lake in the warm season is lake derived. However, better controlled and more detailed studies need to be performed to prove this hypothesis.

Simulations of the isotopic evolution of Great Basin lakes - Further support for this hypothesis is found in the study of Hostetler and Benson (1994), who were able to simulate the daily isotopic composition of Pyramid Lake surface water between October 1987 and October 1989 by using values of 0 and $25 \%$ for $f_{a d}$. They were also able to simulate the mean monthly isotopic composition of Pyramid Lake surface water between July 1985 and January 1992 by using a $0 \%$ value of $f_{a d}$ (see figures $1 \mathrm{a}, 1 \mathrm{~b}$, and 7 of Hostetler and Benson 1994). These results indicate that we may be able to simulate the Holocene isotopic evolution of Great Basin lakes given appropriate climate input in the form of proxy-climate data or climate scenarios. 
Table 4. Calculated concentrations of water vapor in moist air at Reno and Pyramid Lake for vapor-extraction experiments conducted between May and November 1988 and in June 1989: $T_{\mathrm{A}}$-air temperature ( $\left.{ }^{\circ} \mathrm{K}\right)$; RH-relative humidity/100; $\mathrm{AH}-$ absolute humidity $\left(\mathrm{g} \mathrm{m}^{-3}\right)$.

\begin{tabular}{|c|c|c|c|c|c|c|c|}
\hline & \multicolumn{3}{|c|}{ Pyramid Lake sites* } & \multicolumn{3}{|c|}{ Reno at Royal Drive $\dagger$} & \multirow{2}{*}{$\begin{array}{c}\text { Lake } \\
\text { derived } \\
\text { (\%) }\end{array}$} \\
\hline & $T_{\mathrm{A}}$ & RH & $\dot{\mathrm{A} H}$ & $T_{\wedge}$ & $\mathbf{R H}$ & $\mathbf{A H}$ & \\
\hline \multicolumn{8}{|c|}{ Sutcliffe } \\
\hline 26 May 88 & 292.85 & 0.35 & 5.98 & 295.37 & 0.14 & 2.76 & 54 \\
\hline 3 Jun 88 & 299.45 & 0.17 & 4.23 & 298.71 & 0.12 & 2.86 & 32 \\
\hline 10 Jun 88 & 288.65 & 0.42 & 5.58 & 297.04 & 0.13 & 2.82 & 50 \\
\hline 15 Jun 88 & 294.05 & 0.54 & 9.93 & 304.82 & 0.10 & 3.33 & 66 \\
\hline 29 Jun 88 & 296.65 & 0.55 & 11.77 & 305.37 & 0.15 & 5.15 & 56 \\
\hline 29 Jun 88 & 286.15 & 0.37 & 4.21 & 294.82 & 0.22 & 4.21 & 0 \\
\hline 13 Jul 88 & 307.15 & 0.10 & 3.77 & 299.82 & 0.13 & 3.30 & 12 \\
\hline $20 \mathrm{Jul} 88$ & 306.15 & 0.21 & 7.54 & 304.26 & 0.02 & 0.64 & 91 \\
\hline 27 Jul 88 & 302.75 & 0.30 & 8.99 & 297.59 & 0.70 & 15.87 & $<0$ \\
\hline 3 Aug 88(a) & 296.25 & 0.52 & 10.86 & 303.15 & 0.17 & 5.19 & 52 \\
\hline 3 Aug 88(b) & 296.25 & 0.52 & 10.86 & 303.15 & 0.17 & 5.19 & 52 \\
\hline 3 Aug $88(\mathrm{c})$ & 297.45 & 0.58 & 13.00 & 304.26 & 0.15 & 4.86 & 63 \\
\hline 3 Aug 88(d) & 297.45 & 0.58 & 13.00 & 304.26 & 0.15 & 4.86 & 63 \\
\hline 3 Aug $88(\mathrm{e})$ & 299.05 & 0.66 & 16.24 & 302.59 & 0.12 & 3.55 & 78 \\
\hline 15 Aug 88 & 297.15 & 0.26 & 5.69 & 297.04 & 0.08 & 1.73 & 70 \\
\hline 26 Aug 88 & 296.95 & 0.29 & 6.28 & 293.71 & 0.40 & 7.19 & $<0$ \\
\hline 21 Sep 88 & 289.75 & 0.47 & 6.68 & 292.04 & 0.24 & 3.90 & 42 \\
\hline 20 Oct $88(a)$ & 292.25 & 0.41 & 6.77 & 296.48 & 0.15 & 3.15 & 53 \\
\hline 20 Oct $88(b)$ & 291.65 & 0.37 & 5.89 & 296.48 & 0.15 & 3.15 & 46 \\
\hline 3 Nov 88 & 293.25 & 0.21 & 3.66 & 290.93 & 0.37 & 5.64 & $<0$ \\
\hline 28 Nov 88 & 286.85 & 0.43 & 5.12 & 282.04 & 0.20 & 1.75 & 66 \\
\hline 12 Jun 89 (a) & 297.85 & 0.45 & 10.29 & 303.15 & 0.12 & 3.65 & 65 \\
\hline 12 Jun $89(b)$ & 297.85 & 0.45 & 10.29 & 303.15 & 0.12 & 3.65 & 65 \\
\hline 12 Jun $89(\mathrm{c})$ & 301.65 & 0.29 & 8.17 & 300.93 & 0.10 & 2.70 & 67 \\
\hline 12 Jun $89(d)$ & 301.65 & 0.29 & 8.17 & 300.93 & 0.10 & 2.70 & 67 \\
\hline \multicolumn{8}{|c|}{ Deepsite } \\
\hline 6 Sep 88(a) & 299.55 & 0.37 & 9.30 & 306.48 & 0.09 & 3.27 & 65 \\
\hline 6 Sep 88(b) & 299.55 & 0.37 & 9.30 & 306.48 & 0.09 & 3.27 & 65 \\
\hline 6 Sep 88(c) & 306.65 & 0.32 & 11.84 & 307.04 & 0.06 & 2.24 & 81 \\
\hline 6 Sep $88(d)$ & 306.65 & 0.32 & 11.84 & 307.04 & 0.06 & 2.24 & 81 \\
\hline 13 Jun 89 (a) & 300.55 & 0.18 & 4.76 & 304.82 & 0.04 & 1.33 & 72 \\
\hline 13 Jun 89(b) & 300.55 & 0.18 & 4.76 & 304.82 & 0.04 & 1.33 & 72 \\
\hline \multicolumn{8}{|c|}{ Southshore } \\
\hline 20 Jun 88 & 297.45 & 0.56 & 12.55 & 304.26 & 0.10 & 3.23 & 74 \\
\hline 7 Sep 88(a) & 298.95 & 0.23 & 5.57 & 306.48 & 0.05 & 1.82 & 67 \\
\hline 7 Sep 88(b) & 298.95 & 0.23 & 5.57 & 306.48 & 0.05 & 1.82 & 67 \\
\hline \multicolumn{8}{|c|}{ Northshore } \\
\hline 7 Sep $88(a)$ & 299.65 & 0.18 & 4.53 & 301.48 & 0.13 & 3.62 & 20 \\
\hline 7 Sep 88(b) & 299.65 & 0.18 & 4.53 & 301.48 & 0.13 & 3.62 & 20 \\
\hline
\end{tabular}

* Barometric pressure, $895 \mathrm{mb}$.

† Barometric pressure, $865 \mathrm{mb}$.

Suggestions for improvement of experimental design-Lake-atmosphere interactions are more complicated than the steady state conceptual model of Craig and Gordon (1965). The results of this study indicate that values of $\delta_{v}$ vary with distance above the lake surface. Consequently the time over which the extractions occur is short relative to the time over which the mixed layer is homogenized, indi- cating that measurements of $\delta_{v}, T_{\mathrm{A}}$, and $\mathrm{RH}$ should be made as close as possible to the lake surface. Once problem that may prove insurmountable is the horizontal scale of such measurements; i.e. moisture derived by evaporation is incorporated in the air parcel throughout its entire trajectory above the lake surface, but the extraction occurs at only one point along that trajectory. To improve the representa- 
tiveness of the extraction, we suggest that the measurement be made from a moving platform (boat) or that several sequential measurements be made from different on-lake sites.

The character of the base of the mixed layer-We suggest the hypothesis that during times of evaporation, the base of the mixed layer is composed of moisture that is entirely lake derived (i.e. $\delta_{v}=\delta_{e}$ ). The existence and thickness of a thin film of lake-derived vapor is dependent on the flux of evaporated moisture to the film vs. the vertical flux of vapor from the film to the overlying air mass. When windspeeds are high, RH is low and evaporation rates are low, the advected air parcel can strip away the film; but, when windspeeds are low, $\mathrm{RH}$ is high and evaporation rates are high, the film increases in thickness. Quantification of these qualitative concepts has not been accomplished. Measurements at the appropriate spatial and temporal scales have not been done on any lake system which would allow us to estimate the range of conditions under which the thin film is maintained. In addition, predictive, physically based isotopic models (other than the one discussed by Hostetler and Benson 1994) have not been used to test the viability of our hypothesis. If this hypothesis is correct, however, modeling of the isotopic evolution of lake systems would be greatly simplified.

\section{References}

Benson, L. V. 1994. Stable isotopes of oxygen and hydrogen in the Truckce River-Pyramid Lake surfacewater system. 1. Data analysis and extraction of paleoclimatic information. Limnol. Oceanogr. 39: 345355.

, AND H. KLIEFORTH. 1989. Stable isotopes in precipitation and ground water in the Yucca Mountain region, southern Nevada: Paleoclimatic implications, p. 41-59. In D. H. Peterson [ed.], Aspects of climate variability in the Pacific and western Americas. Am. Geophys. Union Geophys. Monogr. 55.

Craig, H., AND L. I. GoRdon. 1965. Isotopic oceanography: Deuterium and oxygen-18 variations in the ocean and marine atmosphere. Univ. R.I. Occas. Publ. 3, p. 277-374.

Farnsworth, R. K., E. S. Thompson, and E. L. Peck. 1982. Evaporation atlas for the contiguous 48 United States. NOAA Tech. Rep. NWS-33.

Fontes, J.-C., AND R. GonfiAntinI. 1970. Composition isotopique et origine de la vapeur d'eau atmospherique dans la region Lac Leman. Earth Planet. Sci. Lett. 7: 325-329.

- - AND M. A. Roche. 1970. Deuterium et oxygene-18 dans les caux du Lac Tchad, p. 387-404. In Isotope Hydrol. 1970 IAEA.

Hostetler, S., AND L. V. BeNson. 1990. Paleoclimatic implications of the high stand of Lake Lahontan derived from models of evaporation and lake level. Clim. Dynam. 4: 207-217.

- AND -1993 . Meteorological and watertemperature data for Pyramid Lake, Nevada 198789. U.S. Geol. Surv. Open-File Rep. 92-159.

- AND - 1994. Stable isotopes of oxygen and hydrogen in the Truckee River-Pyramid Lake surface-water system. 2. A predictive model of $\delta^{18} \mathrm{O}$ and $\delta^{2} \mathrm{H}$ in Pyramid lake. Limnol. Oceanogr. 39: 356-364. IAEA. 1970. Isotope hydrology 1970. Proc. Int. Conf.

1979. Isotopes in lake studies. Proc. Advisory Group Meeting.

LIST, R. J. 1984. Smithsonian meteorological tables, 6th ed. Smithsonian.

MAJOUBE, M. 1971. Fractionnement en oxygene-18 et en deuterium entre l'eau et sa vapor. J. Chim. Phys. 197: 1423-1436.

MerLivat, L., AND J. Jouzel. 1979. Global climatic interpretation of the deuterium-oxygen 18 relationship for precipitation. J. Geophys. Res. 84: 5029-5033.

RicharDS, J. M. 1971. Simple expression for the saturation vapour pressure of water in the range $-50^{\circ}$ to $140^{\circ}$. Brit. J. Appl. Phys. 4: L15-L18.

Sutton, O. G. 1977. Micrometeorology. Krieger.

ZimmermanN, U., and D. H. EhHalt. 1970. Stable isotopes in study of water balance of Neusiedler See, Austria. Invest. of the reliability of the stable isotope method, p. 129-138. In Isotope hydrology 1970. IAEA.

Submitted: 2 September 1993 Accepted: 12 April 1994 Amended: 3 May 1994 